\title{
Kurklareli İlinin Hayvansal Atık Potansiyelinin Biyogaz Üretimi Çerçevesinde Değerlendirilmesi ve Güncel Yapının Yorumlanması
}

\author{
Emre KALAYCI $^{1 *}$, Gökhan TÜRKER ${ }^{2}$, Evren ÇAĞLARER ${ }^{1}$ \\ ${ }^{1}$ Kırklareli Üniversitesi, Fen Bilimleri Enstitüsü, Kırklareli \\ ${ }^{2}$ Kadir Has Üniversitesi, Biyoenformatik ve Genetik Bölümü, İstanbul \\ (ORCID: 0000-0003-2566-9192) (ORCID: 0000-0001-8073-5151) (ORCID: 0000-0002-1343-4751)
}

\begin{abstract}
$\ddot{O} z$
Gelişen teknoloji, artan nüfus ve yaşam standartlarındaki değişiklikler ile orantılı olarak büyüyen ihtiyaca karşılık, başta fosil kökenliler olmak üzere kaynaklardaki azalma, enerjide verimliliği ve yenilenebilir kaynakların etkin ve yaygın kullanımını kaçınılmaz kılmıştır. Bu kaynaklardan biri de, organik atıkların oksijensiz ortamda fermente edilmesi ile elde edilen biyogazdır. Bu gaz; dünyada, petrol, kömür ve doğal gazdan sonra, enerji kaynağı olarak dördüncü sırayı almakta ise de, yenilenebilir olması ile bu sıralamanın ötesi bir değeri haizdir. Keza kolay ulaşılabilirliği, çevreye olumsuz etkisinin azlığı ve atık bertarafı yönü ile de önemli avantajlara sahiptir. Biyokütle olarak kullanılan hayvansal atıklar, organik atıklar arasında miktar itibari ile önemli bir yerde bulunmaktadır. Kolay ve yoğun miktarlarda bulunması bu atıkları biyogaz tesisleri için ideal bir yakıt olarak öne çıkarmaktadır. Kırklareli ili gerek hayvancıllk gerekse bunu destekleyen tarımsal faaliyetler bakımından ülkemizde önemli bir yere sahiptir. TÜIK verilerine göre, 2018 yılında Kırklareli ilinde büyükbaş hayvan 148.123, küçükbaş hayvan sayıs 534.890 , kanatlı hayvan sayısı da toplamda 586.403 olarak tespit edilmiştir. Kırklareli ilindeki hayvan sayıları, biyogaz üretimi için ciddi bir potansiyelin varlı̆̆ını göstermektedir. Bu kapsamda bu atıklardan üretilebilecek maksimum ve kullanılabilir biyogaz potansiyellerinin tespit edilmesi ile hem bölgenin enerji üretimi ve atık bertaraf kapasitesi belirlenmiş, hem de olası yatırımlara yön verebilmek açısından önemli veriler elde edilmiş olur. 2018 yılı değerleri ile beslenen çiftlik hayvanlarından üretilebilecek biyogaz miktarı $86.503 .832 \mathrm{~m} 3 /$ yıldır. Bu çalışmada; hayvansal atıklar-biyogaz ilişkisi, biyogaz üretim sürecine etki eden faktörler, biyogaz üretiminde kullanılan atıkların tanımlanması ile Kırklareli ili özelinde mevcut hayvansal atık kaynaklı biyogaz potansiyelinin belirlenmesi ve yorumlanması ile geleceğe dönük öneriler irdelenmiştir.
\end{abstract}

Anahtar kelimeler: Hayvansal atık, Biyogaz, Biyogaz üretimi, Kırklareli, Havasız çürütme.

\section{Investigation of Manure Potential of City of Kirklareli in Respect of Biogas Production and Evaluation of Current Structure}

\begin{abstract}
Increase in the demands due to advancing technology, changes in life standards and increasing human population, along with decreasing fossil fuel reserves, inevitably leads us to energy efficiency and effective use of renewable energy sources. Anaerobic digestion of organic wastes producing biogas, which contains valuable methane, is one of the renewable energy sources. Biogas stands in the fourth place in energy source ranking after petroleum, coal and natural gas, but has a special value due to its renewable source. It has many advantages like being easy to access, having minimal environmental impact and elimination of wastes. Manure has a special place among organic wastes. Manure is easy to access and can be present in high amounts which makes it a perfect substrate for biogas operations. City of Kirklareli has a deserved place in respect of animal husbandry and agricultural activities. According to data of TUIK, in 2018 animal populations are recorded as follows; 148.123 bovine, 534.890 ovine and 586.403 poultry. Animal Population of Kirklareli shows a great potential for biogas production. Determination of maximum and optimum biogas potential from these animals is important in respect of energy generation, waste elimination and directing new investments. According to calculations, 81.506.628 m3/year biogas can be produced from digestion of domestic animal manure. In this study, relations between animal manure
\end{abstract}

*Sorumlu yazar: emre_06@hotmail.com

Geliş Tarihi: 19.07.2019, Kabul Tarihi: 18.10.2019 
and biogas, parameters affecting biogas production, identification of suitable wastes are investigated along with biogas potential of animal manure in Kirklareli and suggestions toward the future..

Keywords: Animal manure, Biogas, Biogas production, Kirklareli, Anaerobic digestion.

\section{Giriş}

Fosil esaslı yakıt rezervleri, plansız endüstriyel kullanımları sebebiyle yakın zamanda tükenme sorunu ile karşı karşıyadır. Enerji ve Tabii Kaynakları Bakanlığı verilerine göre, dünyadaki toplam rezervi 2015 yılı sonu itibari ile 1,7 trilyon varil civarında olan petrol, 51 yıllık tüketimi ancak karşılayabilecek seviyededir. Aynı dönem için 187 trilyon $\mathrm{m}^{3}$ olarak belirlenmiş olan doğal gaz rezervi 53 yıl gibi bir süre için yeterlidir. Dünya kömür rezervleri ise, 114 yıl boyunca ihtiyacı karşılamaya yeterli olup, tüm yakıtlar arasında en yüksek üretim oranına sahiptir [1].

Fosil kökenli enerji kaynaklarının sınırlı olması, tüm dünyada alternatif ve yenilenebilir enerji kaynakları üzerine çalışmaların yoğunlaşmasına sebep olmuştur. Bu anlamda Türkiye her zamankinden daha fazla konuya eğilmek durumundadır. Çünkü yoğun ihtiyaca karşıık, mevcut enerji kaynaklarından yeterince yararlanma noktasında istenen düzeyde değildir. Bu ihtiyacı karşılamada, özellikle tarım ve hayvancılık alanında gelişmiş ülkelerde bugün yaygın kullanılan yenilenebilir enerji kaynaklarından biri olarak biyogazın önemli bir yeri vardır [2]. Türkiye, birincil enerji kaynaklarında $\% 72,6$ oranında dışa bağımlıdır [3]. Bu nedenle, ülkemizin dışa bağımlılığının azalması ve kendi kendine yetebilir olması açısından yenilenebilir enerji kaynakları teknolojisinin geliştirilmesi ve kullanımın yaygınlaştırılması kaçınılmazdır [4].

2010 yılı için AB ülkelerinin biyogaz altyapısı Tablo 1'de verilmiştir. Bu kapsamda Almanya ve İngiltere toplamda 6.000 kiloton petrol eşdeğeri ile diğer tüm ülkelerin toplamı kadar enerji üretmektedir. $\mathrm{Bu}$ değerler, ülkelerin gelişmişlikleri ile biyogaz üretimi arasında önemli ölçüde bir ilişkinin varlığını göstermektedir [5].

Tablo 1. AB ülkeleri 2010 yılı biyogaz üretim durumu

\begin{tabular}{|c|c|c|c|c|c|}
\hline & Ülke & $\begin{array}{l}\text { Çöpgazı } \\
\left(\text { ktpe*) }^{*}\right.\end{array}$ & $\begin{array}{c}\text { Arıtma çamuru gazı } \\
\text { (ktpe) }\end{array}$ & $\begin{array}{c}\text { Biyogaz } \\
\text { (ktpe) }\end{array}$ & $\begin{array}{c}\text { Toplam } \\
\text { (ktpe) }\end{array}$ \\
\hline 1 & Almanya & 265,5 & 386,7 & $3.561,2$ & $4.213,4$ \\
\hline 2 & İngiltere & $1.474,4$ & 249,5 & 0,0 & $1.723,9$ \\
\hline 3 & Fransa & 440,3 & 45,2 & 38,7 & 526,5 \\
\hline 4 & İtalya & 361,8 & 5,0 & 77,5 & 444,3 \\
\hline 5 & Hollanda & 39,2 & 48,9 & 179,8 & 267,9 \\
\hline 6 & İspanya & 140,9 & 10 & 32,9 & 183,7 \\
\hline 7 & Avusturya & 4,9 & 18,9 & 141,2 & 165,1 \\
\hline 8 & Çekya & 29,2 & 33,7 & 67 & 129,9 \\
\hline 9 & Belçika & 44,3 & 2,1 & 78,2 & 124,7 \\
\hline 10 & İsveç & 34,5 & 60 & 14,7 & 109,2 \\
\hline 11 & Danimarka & 6,2 & 20 & 73,4 & 99,6 \\
\hline 12 & Polonya & 35,5 & 58 & 4,5 & 98 \\
\hline 13 & Yunanistan & 46,3 & 12,2 & 0,2 & 58,7 \\
\hline 14 & Finlandiya & 30,6 & 10,7 & 0,0 & 41,4 \\
\hline 15 & İrlanda & 23,6 & 8,1 & 4,1 & 35,8 \\
\hline 16 & Macaristan & 2,8 & 10,3 & 17,5 & 30,7 \\
\hline 17 & Portekiz & 0 & 0 & 23,8 & 23,8 \\
\hline 18 & Slovenya & 8,3 & 3 & 11 & 22,4 \\
\hline 19 & Slovakya & 0,8 & 14,8 & 0,7 & 16,3 \\
\hline 20 & Lüksemburg & 0 & 0 & 12,3 & 12,3 \\
\hline 21 & Letonya & 7 & 2,7 & 0 & 9,7 \\
\hline 22 & Litvanya & 1,30 & 2,10 & 1,20 & 4,7 \\
\hline 23 & Estonya & 2 & 0,9 & 0,9 & 3,8 \\
\hline 24 & Romanya & 0,10 & 0,70 & 0,50 & 1,3 \\
\hline \multicolumn{5}{|c|}{ TOPLAM } & $8.347,1$ \\
\hline
\end{tabular}

* Kiloton Petrol Eşdeğeri 
Biyogaz; organik esaslı atıkların oksijensiz ortamda fermantasyonu sonucu ortaya çıkan renksiz, kokusuz, havadan hafif, parlak mavi bir alevle yanan ve ağırlıklı olarak \% 40-70 metan, \% 30-60 karbondioksitten oluşur. Bu iki gazın biyogaz içerisindeki toplamı yaklaşık olarak \% 97-98 oranındadır. Biyogaz, metan ve karbondioksite ilave olarak eser miktarda hidrojen sülfür $\left(\mathrm{H}_{2} \mathrm{~S}\right)$, azot $\left(\mathrm{N}_{2}\right)$, oksijen $\left(\mathrm{O}_{2}\right)$, karbon monoksit $(\mathrm{CO})$ ve hidrojen $\left(\mathrm{H}_{2}\right)$ gibi gazları da içerebilmektedir [1,17].

Anaerobik çürütmede en sık kullanılan substrat hayvansal dışkı ve zirai atıklardır [5]. Bu kapsamda resmi ve bilimsel kaynaklardan elde edilen biyogaz potansiyeli Tablo 2'de görülmektedir. Hayvansal dışkılar her ne kadar az biyogaz potansiyeline sahip olsalar da, kolay ve yüksek miktarlarda bulunmaları açısından biyogaz üretiminin başlıca besi kaynağıdırlar [6].

Tablo 2. Farklı atıkların organik kuru madde (OKM) ve taze ağırlığına bağlı biyogaz verimleri [16,17].

\begin{tabular}{|c|c|c|c|c|}
\hline \multirow[t]{2}{*}{ Atık } & \multicolumn{2}{|c|}{$\begin{array}{c}\text { Organik Kuru Maddenin } \\
\text { Biyogaz Verimi } \\
\mathrm{m}^{3} / \text { ton OKM }\end{array}$} & \multicolumn{2}{|c|}{$\begin{array}{c}\text { Toplam Taze Atığın Biyogaz } \\
\text { Verimi, } \mathrm{m}^{3} / \text { ton }\end{array}$} \\
\hline & $\begin{array}{c}\text { Tarım } \\
\text { Bakanlığı }\end{array}$ & $\begin{array}{l}\text { Deublein ve } \\
\text { Steinhauser }\end{array}$ & $\begin{array}{c}\text { Tarım } \\
\text { Bakanlı̆̆ı }\end{array}$ & $\begin{array}{l}\text { Deublein ve } \\
\text { Steinhauser }\end{array}$ \\
\hline Sığır Dışkısı & $90-310$ & $100-800$ & $9-30$ & $10-77$ \\
\hline Kanatlı Dışkısı & $310-620$ & $300-800$ & $55-110$ & $53-140$ \\
\hline Domuz Dışkısı & $340-550$ & $270-450$ & $14-22$ & $11-18$ \\
\hline Buğday Saman & $200-300$ & 500 & $128-192$ & 360 \\
\hline Arpa Samanı & $290-310$ & 500 & $186-198$ & 360 \\
\hline Sebze Artıkları & $330-360$ & 400 & $43-77$ & 85 \\
\hline Ziraat Atıkları & $310-430$ & $400-800$ & $66-91$ & $90-180$ \\
\hline Çimen & $280-550$ & $700-800$ & $56-110$ & $140-160$ \\
\hline Ağaç Yaprakları & $210-290$ & 600 & $50-70$ & 144 \\
\hline Atıksu Çamuru & $310-800$ & $700-1200$ & $62-160$ & $140-240$ \\
\hline
\end{tabular}

Biyogaz, anaerobik ortamda, organik atıkların uygun mikroorganizmaların etkisiyle fermentasyonu sonucu ortaya çıkan bir nihai üründür [28]. Diğer bir deyişle, biyogaz üretiminde bakteriler için temel enerji kaynağı organik atık ve artıklardır [26,27]. Bu bakteri grupları, genellikle organik madde içinde kendiliğinden bulunduğundan, sıcaklık başta olmak üzere, uygun koşullarda aktif hale gelerek biyogaz oluşumuna sebep olmaktadırlar. Burada, biyogaz üretiminin yanı sıra, sürecin sonunda ortaya çıkan fermente ürün içerik olarak zengindir ve gübre olarak kullanılabilmektedir. Biyogaz üretimi süreci sonunda çevresel açıdan kirletici bir unsur olan organik atık, hem biyogaz gibi değerli bir enerji kaynağına, hem de çevre dostu bir organik gübreye dönüşmektedir [17,29,30].

Biyogaz, çeşitli mikroorganizmaların aktiviteleri sayesinde dört ana basamakta oluşmaktadır. Biyokütle içerisindeki karbonhidratlar, yağlar, proteinler gibi büyük moleküllü karbon kaynakları bu dört faz ile metan ve karbondioksite kadar parçalanmaktadır (Şekil 1) [7]. Hidroliz fazında karbonhidratlar, yağlar ve proteinler gibi büyük moleküllü bileşikler daha küçük yapı taşları olan amino asitler, yağ asitleri ve monosakkaritlere parçalanır [8,9]. Oluşan küçük moleküllü bileşikler asidojenez fazı ile laktat, etanol, bütirat, propionat gibi çok karbonlu yăg asitlerine [10], daha sonra da asetojenez fazı ile asetik asit, karbondioksit ve hidrojene parçalanır [11]. Son aşama olan metanojenez aşamasında ise asetik asit, karbondioksit ve hidrojen biyogaza dönüştürülür. Süreç sonunda biyogaza dönüşmeyen organik madde, yapısal olarak daha stabil bir hale gelmiş olarak sistemi gübre etkisi olan fermente ürün olarak terk eder [12]. 


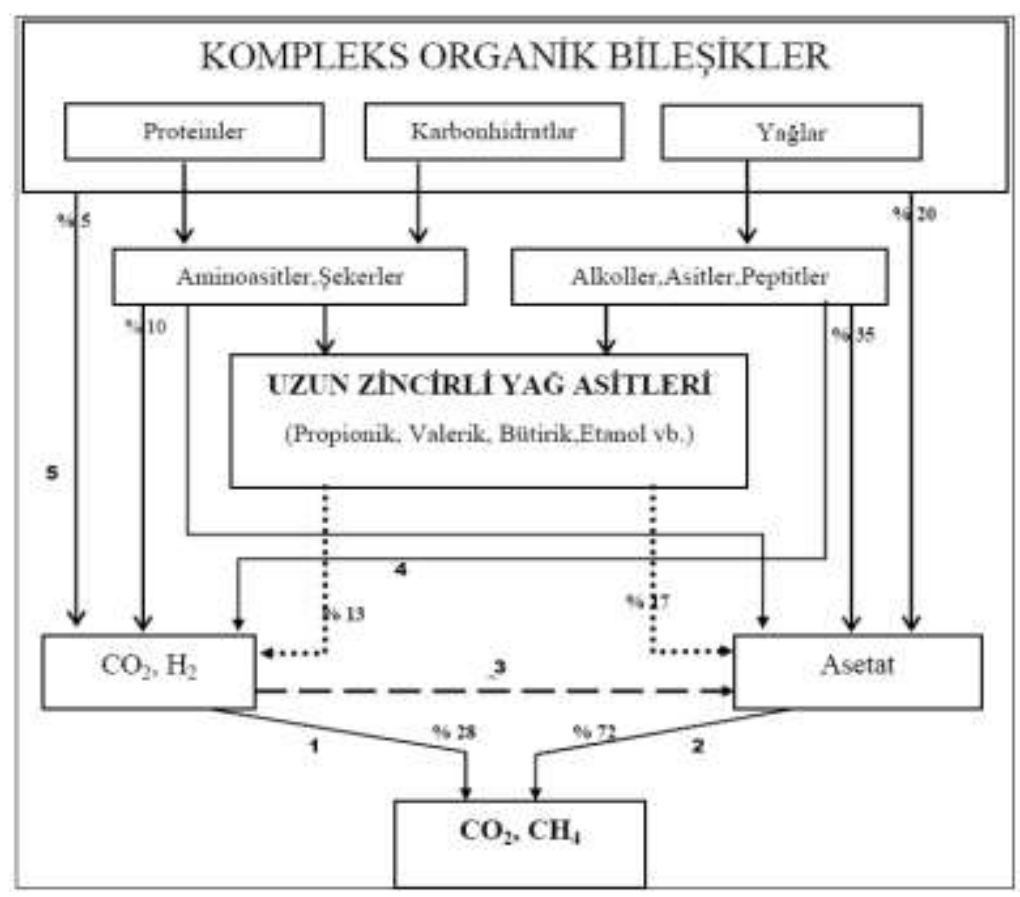

Şekil 1. Biyogaz üretim sürecinin fazları [6].

Anaerobik çürütme prosesi, içeriğindeki canlı mikroorganizmalar sebebiyle kompleks bir prosestir. Dolayısıyla hedeflenen biyogaz miktarını ve içeriğini sağlayabilmek için üretim prosesine etkisi olan çevresel ve operasyonel parametrelerin kontrolü önemlidir.

Anaerobik bakterilerin en önemli besin maddeleri, fermentöre beslenen hammaddelerden temin ettikleri karbon ve azottur. Bakteriler, karbonu enerji kaynağı olarak kullanırken, azotu yeni hücreler oluşturabilmek için yapı malzemesi olarak değerlendirirler. Bu kapsamda karbon ve azot miktarları arasında bir denge olmalıdır. Karbon/ azot (C/N) oranının 20/1 olması hayvansal atıkların havasız çürütme süreci için optimum orandır. Bu oranın altında kalınması halinde, reaktörde biyogaz üretimine olumsuz etki eden amonyak oluşurken, üstü değerlerde de, inhibitör etkisi göstererek biyogaz üretimini yavaşlatan uçucu yağ asitlerinin ortaya çıkması söz konusudur [23,24].

Öte yandan, taze hayvan gübreleri bu oranı kendiliğinden sağlar, bu sebeple ayrıca oran ayarlanmasına ihtiyaç duyulmaz. Kuru bazda $\mathrm{C} / \mathrm{N}$ oranları, sığır gübresinde 18 , koyun gübresinde 22 ve kümes hayvanları gübresinde de 14 olarak ortaya konmuştur [25].

Bunun yanında hammadde cinsi, miktarı ve kuru madde oranı besini oluşturan yapıyla doğrudan bağlantılı oldukları için son derece önemli parametrelerdir. Biyogaz üretiminde yer alan mikroorganizmalar ile hammaddenin partikül büyüklüğ̈̈, ortamın asitliği ve bu buluşmanın süresi reaksiyonların hızını belirlediği için ayrıca önem arz etmektedir. Diğer taraftan ortam sıcaklığı reaksiyonların hızını büyük ölçüde etkilediğinden, gaz oluşumunda en önemli etkendir. Bu nedenle, özellikle sabit tutulmaya çalışılan parametrelerden biridir [22].

\section{Materyal ve Metot}

Kırklareli ili hayvansal kaynaklı biyogaz potansiyelinin belirlenmesi için hayvansal üretim miktarları hayvan sayıları ve yaklaşık atık oluşumları 1şığında hesaplanmıştır. Hayvansal popülasyon verileri Türkiye İstatistik Kurumu (TUIKK)'nun 2018 yılı veri bankasından alınmıştır.

Biyogaz üretimlerinin hesaplanması için hayvansal atı üretim verileri ve atıkların biyogaz verimleri kullanılmıştır. Bu kabullerde gerek literatürdeki veriler [18,19,27], gerekse varolan tam ölçekli tesislerin işletme verileri dikkate alınmıştır (Tablo 3).

2018 TÜIKK verilerine bağlı olarak her ilçedeki hayvan popülasyonundan üretilecek atık miktarı ve üretilecek biyogaz potansiyeli Tablo 3'te verilen değerler yardımıyla hesaplanmıştır. Tablo 7'deki veriler esas alınarak, biyogaz potansiyeline dayalı elektriksel kurulu güçler hesaplanmış ve Tablo 8'de sunulmuştur. 
Ayrıca biyogaz enerjisinin elektrik dışında farklı yakıt tiplerine karşılık gelen miktarları içinde kabuller ışı̆̆ında gerekli hesaplamalar yapılmıştır [20,21] (Tablo 4).

Tablo 3. Kabullerde kullanılan üretim değerleri [27].

\begin{tabular}{|c|c|c|}
\hline & $\begin{array}{l}\text { Ortalama Atık } \\
\text { Üretimi (kg/gün) }\end{array}$ & $\begin{array}{c}\text { Ortalama Biyogaz } \\
\left.\text { Potansiyeli ( } \mathrm{m}^{3} / \text { ton }\right)\end{array}$ \\
\hline Büyükbaş Hayvan & 30 & 33 \\
\hline Küçükbaş Hayvan & 2,25 & 58 \\
\hline Yumurta Tavuğu & 0,08 & 78 \\
\hline
\end{tabular}

Tablo 4. $1 \mathrm{~m}^{3}$ biyogazın farklı yakıt tipleri için enerji eşdeğerleri [1].

\begin{tabular}{|c|c|c|c|c|c|c|c|}
\hline & Elektrik & Gaz & Motorin & Butan & Propan & Kömür & Odun \\
\hline $1 \mathrm{~m}^{3}$ Biyogaz & $4,7 \mathrm{kWh}$ & $0,62 \mathrm{~L}$ & $0,66 \mathrm{~L}$ & $0,43 \mathrm{~kg}$ & $0,25 \mathrm{~m}^{3}$ & $1,46 \mathrm{~kg}$ & $3,47 \mathrm{~kg}$ \\
\hline
\end{tabular}

Kırklareli ili hayvansal kaynaklı biyogaz potansiyelinin hesaplanmasında büyükbaş hayvan dışkısı, küçükbaş hayvan dışkısı ve yumurta tavuğu dışkısı dikkate alınmıştır.

\section{Bulgular ve Tartışma}

\subsection{Kırklareli İlinin Hayvansal Verileri}

Kırklareli ili Trakya bölgesinin hayvancılık ve tarım yönünden önde gelen ilidir. Uygun coğrafi durumu sebebiyle, büyükbaş hayvancılık ve buna bağlı geniş bir tarım ürünü yelpazesine bağlı tarım bölgede öne çıkmaktadır. Ayrıca Kırklareli, İstanbul'a yakın oluşu ile endüstriyel anlamda da kendine yer edinmiștir. Keza, hayvan hastalıklarından ari bölge olarak ilan edilen coğrafyada bulunması, hayvan popülasyonunun fazlalığı açısından olumlu etki yapmaktadır. Bu kapsamda Türkiye İstatistik Kurumu'ndan (TÜIK) alınan güncel hayvan popülasyon verileri Tablo 5'te verilmiştir.

Tablo 5. 2018 yılı Kırklareli ili hayvan sayıları [15].

\begin{tabular}{|l|c|c|c|}
\hline İlçe/Hayvan Sayısı & Büyükbaş & Küçükbaş & Kanatlı \\
\hline Merkez & 41.231 & 187.881 & 320.390 \\
\hline Lüleburgaz & 46.246 & 106.005 & 157.342 \\
\hline Babaeski & 27.907 & 61.368 & 48.522 \\
\hline Vize & 12.580 & 51.021 & 9.240 \\
\hline Pınarhisar & 7.463 & 60.452 & 10.858 \\
\hline Demirköy & 5.933 & 18.820 & 27.050 \\
\hline Pehlivanköy & 3.037 & 8.405 & 7.109 \\
\hline Kofçaz & 3.726 & 40.938 & 5.892 \\
\hline TOPLAM & $\mathbf{1 4 8 . 1 2 3}$ & $\mathbf{5 3 4 . 8 9 0}$ & $\mathbf{5 8 6 . 4 0 3}$ \\
\hline
\end{tabular}

Bölge tarımsal arazileri ve hayvan sayıları dikkate alındığında, özellikle Merkez, Lüleburgaz ve Babaeski ilçeleri sınırları içinde, hayvansal atıkların bir çevre problemi olduğu görülmektedir. Kabul edilen veriler ışığında bu ilçelerde sadece büyükbaş hayvanlardan üretilen atık miktarları yaklaşık olarak sırasıyla 1.650 ton/gün, 1.850 ton/gün ve 1.116 ton/gün olmaktadır. Bu atığın her gün oluştuğu ve bertaraf edilmesinin gerekliliği, üzerinde dikkatle durulması gereken bir konudur.

\subsection{Kurklareli İlinin Biyogaz Potansiyeli}

Tablo 5'te verilen değerler ışığında Kırklareli iline bağlı ilçelerde 2018 y1lı verilerine göre hesaplanan yıllık atık miktarları ve bu atıklara bağlı biyogaz üretim potansiyelleri Tablo 6'da verilmiştir. 
Tablo 6. Kırklareli iline bağlı ilçelerde 2018 yılı verilerine göre hesaplanan atık miktarları ve biyogaz üretimleri.

\begin{tabular}{|l|c|c|c|c|c|c|}
\hline İlçe & $\begin{array}{c}\text { Büyükbaş } \\
\text { Atık } \\
\text { (ton/yıl) }\end{array}$ & $\begin{array}{c}\text { Kanatlı } \\
\text { Atık } \\
(\text { ton/yıl) }\end{array}$ & $\begin{array}{c}\text { Küçükbaş } \\
\text { Atık } \\
(\text { ton/yıl })\end{array}$ & $\begin{array}{c}\text { Büyükbaş } \\
\text { Biyogaz } \\
\left(\mathbf{m}^{3} / \mathbf{y l l}\right)\end{array}$ & $\begin{array}{c}\text { Kanatlı } \\
\text { Biyogaz } \\
\left(\mathbf{m}^{3} / \mathbf{y ı l}\right)\end{array}$ & $\begin{array}{c}\text { Küçükbaş } \\
\text { Biyogaz } \\
\left(\mathbf{m}^{3} / \mathbf{y ı l}\right)\end{array}$ \\
\hline Merkez & 451.479 & 17.541 & 154.297 & 14.898 .822 & 1.368 .225 & 8.949 .242 \\
\hline Lüleburgaz & 506.394 & 8.614 & 87.057 & 16.710 .992 & 671.929 & 5.049 .283 \\
\hline Babaeski & 305.582 & 2.657 & 50.398 & 10.084 .194 & 207.213 & 2.923 .111 \\
\hline Vize & 137.751 & 506 & 41.901 & 4.545 .783 & 39.459 & 2.430 .258 \\
\hline Pınarhisar & 81.720 & 594 & 49.646 & 2.696 .755 & 46.369 & 2.879 .480 \\
\hline Demirköy & 64.966 & 1.481 & 15.456 & 2.143 .890 & 115.517 & 896.444 \\
\hline Pehlivanköy & 33.255 & 389 & 6.903 & 1.097 .420 & 30.359 & 400.351 \\
\hline Kofçaz & 40.800 & 323 & 33.620 & 1.346 .390 & 25.162 & 1.949 .979 \\
\hline TOPLAM & $\mathbf{1 . 6 2 1 . 9 4 7}$ & $\mathbf{3 2 . 1 0 6}$ & $\mathbf{4 3 9 . 2 7 8}$ & $\mathbf{5 3 . 5 2 4 . 2 4 6}$ & $\mathbf{2 . 5 0 4 . 2 3 4}$ & $\mathbf{2 5 . 4 7 8 . 1 4 8}$ \\
\hline
\end{tabular}

Tablo 6'da sunulan veriler dikkate alındığında, Merkez, Lüleburgaz ve Babaeski ilçelerinde biyogaz enerjisi bakımından uygun bir potansiyel olduğu gerçeği ortaya çıkmaktadır. Diğer taraftan bu atıkların tamamının toplanamayacağı, bir miktarının meralarda veya süreçte ulaşılamaz olacağı kabul edilmekte, bu kapsamda elde edilen değerlerin 1/3 oranında azalması beklenmektedir [27]. Bu değerler sadece hayvansal atıkları içerdiğinden, gerçek potansiyelin zirai ve endüstriyel organik atıkların varlığ1 sebebiyle çok daha yüksek olacağı öngörülmektedir.

\subsection{Kırklareli İlinin Biyogaz Kaynaklı Elektrik Üretim Kapasitesi}

Biyogaz üretim santrallerinde kullanılan gaz motorlarının yaygın olarak kabul edilen verimleri ile üretilen biyogaz için kabul edilen değerler de Tablo 7'de sunulmuştur. Kabul edilen bu değerler atıklardan enerji üretimi konusunda gerekli hesaplamalarda kullanılacaktır.

Tablo 7. Biyogazdan enerji dönüşümünde sıklıkla kullanılan kabul değerleri [26].

\begin{tabular}{|l|c|c|}
\hline \multicolumn{1}{|c|}{ Kabul } & Miktar & Birim \\
\hline Metan oranı & $\% 60$ & \\
\hline Metan enerji potansiyeli & 9,97 & $\mathrm{kWth} / \mathrm{m}^{3} . \mathrm{metan}$ \\
\hline Gaz motoru elektrik verimliliği* & $\% 40$ & \\
\hline Gaz motoru ısı verimliliği* & $\% 49$ & \\
\hline Atık ısı kazanı verimliliği* & $\% 88$ & \\
\hline Emre amadelik oranı & $\% 91,3$ & \\
\hline Yıllık işletme süresi & 8.000 & saat/yıl \\
\hline
\end{tabular}

*Kullanılan kabuller Guascor HGM 560 gibi Türkiye pazarında kullanılan gaz motoru verilerinin ortalamalarıdır. Emre amadelik için verimli çalışan bir biyogaz tesisi (Afyon Biyogaz Enerji Santrali) referans alınmıştır. 
Tablo 8. Kırklareli iline bağlı ilçelerde 2018 yılı verilerine göre hesaplanan biyogaz kaynaklı elektriksel kurulu güçleri.

\begin{tabular}{|l|c|c|c|}
\hline İlçe & $\begin{array}{c}\text { Büyükbaş } \\
\text { Kurulu } \\
\text { Gücü } \\
\text { (MWe) }\end{array}$ & $\begin{array}{c}\text { Küçükbaş } \\
\text { Kurulu } \\
\text { Gücü } \\
\text { (MWe) }\end{array}$ & $\begin{array}{c}\text { Kanatll } \\
\text { Kurulu } \\
\text { Gücü } \\
\text { (MWe) }\end{array}$ \\
\hline Merkez & 4,5 & 2,7 & 0,4 \\
\hline Lüleburgaz & 5,0 & 1,5 & 0,2 \\
\hline Babaeski & 3,0 & 0,9 & 0,1 \\
\hline Vize & 1,4 & 0,7 & 0,0 \\
\hline PInarhisar & 0,8 & 0,9 & 0,0 \\
\hline Demirköy & 0,6 & 0,3 & 0,0 \\
\hline Pehlivanköy & 0,3 & 0,1 & 0,0 \\
\hline Kofçaz & 0,4 & 0,6 & 0,0 \\
\hline Toplam & $\mathbf{1 6}$ & $\mathbf{8}$ & $\mathbf{1}$ \\
\hline
\end{tabular}

Yapılan farklı çalışmalarda, başta büyük baş kaynaklı olmak üzere hayvansal atık, dolayısı ile biyogaz potansiyeli yönü ile Kırklareli ilinin gerisinde kalan bölgeler için de biyogaz enerji santrali kurulumun isabetli olacağı sonucuna ulaşılmıştır [26,31,32].

Tablo 8'de sunulan verilerden, Merkez, Lüleburgaz ve Babaeski ilçelerinde değerlendirilmesi gerekli ciddi bir biyogaz potansiyeli olduğu görülmektedir. Hâlihazırda, Kırklareli ili, Lüleburgaz ilçesinde 4,8 MWe ve Babaeski ilçesinde de 4,3 MWe kurulu güce sahip iki adet biyogaz santrali faaliyettedir. Sirasıyla Agman Ovacık Biyogaz Santrali ve Kumrular Biyogaz Santrali adlı bu tesisler, 2019 y1lı Yenilenebilir Enerji Kaynaklar (YEK) Listesine göre henüz sadece \% 10 verimle çalışmaktadırlar. Bölgedeki organik atık potansiyeli göz önüne alındığında, hâla önemli bir boşluk olduğu göze çarpmaktadır. Bu durum, bölgenin gelişimi de dikkate alındığında, başta Babaeski olmak üzere Merkez ve Lüleburgaz ilçelerine yeni biyogaz enerji santrali kurulmasının cazip olduğu sonucunu ortaya koymaktadir.

\section{Sonuç ve Öneriler}

Hayvansal dışkılar \%90’a varan organik madde içerikleri ve yüksek KOİ miktarları (> 50.000 mg O $2 / \mathrm{L})$ sebebiyle ciddi bir çevre kirletici olmakta, bu durum da bu atıkların hızlı ve yararlı bertarafinı önemli ve zorunlu kılmaktadır. Kontrolsüz şekilde çevreye atılan hayvansal atıklar içerdiği patojenler sebebiyle toplum ve hayvan sağlığı açısından risk oluşturmakta, içerdiği azot bileşikleri (nitrat, amonyak, üre vb.) sebebiyle yeraltı ve yerüstü sularını kirleterek ötrofikasyona sebep olmaktadır. Ötrofik sularda, oluşan kokunun yanı sıra, su yüzeyinde toplanan alg ve mikroskopik organizmalar tarafından güneş 1şınlarını engellenerek, su altı yaşamı için hayati öneme sahip oksijen emilimi engellenerek, su ekosisteminin azalması, hatta uzun vadede ölümü söz konusu olabilmektedir. Buna karş1lık, biyogaz üretimi sonucu ortaya çıkan fermente ürün işlenmemiş dışkıya göre son derece yararlı ve kararlı bir üründür. Fermentasyon sonucu yağ asitlerinin farklı yapılara dönüşmesi ile neredeyse kokusuz ve bitkilerin daha iyi özümseyeceği formda ürün eldesi mümkün olmaktadır. Ayrıca çürütme süreci patojenik bakterilerin en az \% 95'ini ve yabani ot tohumları gibi birçok zararlı mikroorganizmayı da yok ederek fermente ürünü daha hijyenik hale getirmektedir.

Biyogaz üretimi özellikle yenilenebilir enerji alanında birçok faydası ile öne çıkan bir teknolojidir. Özellikle atık sınıfı altındaki biyokütleyi bertaraf ederek hem enerji hem de birçok değerli yan ürün üretmesi bakımında birçok katma değeri olan bu süreç, son yıllarda sektördeki etkisini artırmaya başlamıştır. Biyogaz santralleri, başta hayvansal atıklar olmak üzere birçok farklı organik atığı bertaraf ederek; gerek patojen giderimi yaparak çevre ve halk sağlığının korunmasına, gerek nitrat ve diğer azotlu bileşikleri uygun formlara dönüştürerek azotlu bileşikler kaynaklı çevre problemlerinin önlenmesine, gerekse fermente ürünün gübre özelliği sebebiyle sürdürülebilir tarımın desteklenmesine yardımcı olmaktadırlar. 
Veriler, ülkemizin biyogazdan enerji üretimi konusunda, gelişmiş ülkelere göre alması gerekli çok mesafe olduğu gerçeğini ortaya koymakla birlikte, son yıllardaki gelişmeler umut vericidir.

Kırklareli ilinin hayvan sayılarından yola çıkarak ortaya konan atık potansiyeli ve buna bağlı biyogaz üretimi hesaplanmıştır. Bölgede yılda 2.093.331 ton hayvansal kaynaklı atık oluştuğu, bu atıktan $81.506 .628 \mathrm{~m}^{3}$ biyogaz üretilebileceği hesaplanmıştır. Bu da toplamda $24 \mathrm{MW}_{\mathrm{e}}$ kurulu güce karş1lık gelmektedir. Merkez, Lüleburgaz ve Babaeski ilçeleri toplamda bu kurulu gücün $\% 80$ gibi ciddi bir oranını bünyelerinde barındırmaktadır. Kırklareli ili iki adet biyogaz tesisine ev sahipliği yapmaktadır. Ancak yapılan incelemelerde, bu tesislerin kapasite itibari ile bölge atık potansiyelini tam olarak karşılayabilir düzeyde olmadığı değerlendirilmiştir. Bölgenin gelişimi ve tarım potansiyeli de göz önüne alındığında Kırklareli ilinde daha fazla biyogaz tesisine ihtiyaç olduğu öngörülmektedir.

\section{Kaynaklar}

[1] Enerji ve Tabii Kaynaklar Bakanlığı, http://www.yegm.gov.tr/yenilenebilir/biyogaz.aspx (Erişim Tarihi: 10.11.2018).

[2] Topaloğlu B., İmren V. 2011. Samsun İlinde Biyogaz Enerjisi Potansiyeli ve Uygulanabilirliği. Samsun Sempozyumu, 13 Ekim 2011, Samsun.

[3] Şen H.M., 2007. Türkiye'nin Genel Enerji Durumu, Türkiye'de Enerji ve Geleceği. İTÜ Görüşü, 27-35, İstanbul.

[4] Demirbaş A. 2006. Biogas Potential of Manure and Straw Mixtures. Energy Sources, Part A, 28: 71-78.

[5] Weiland P. 2010. Biogas Production: Current State And Perspectives. Applied Microbiology And Biotechnology, 85: 849-860.

[6] Kaya D., Çağman S., Eyidoğan M., Yağmur A., Akgün F., Tırıs M. 2008. Biyogaz Üretim ve Enerji Teknolojileri. TÜBİTAK MAM, Enerji Enstitüsü, Gebze/ Kocaeli.

[7] Zinder S.H., Cardwell S.C., Anguish T., Lee M., Koch M. 1984. Methanogenesis in a Thermophilic (58C) Anaerobic Digester: Methanothrix sp. as an İmportant Acetoclastic Methanogen. Applied and Environmental Microbiology, 47: 796-807.

[8] Khanal S.K., Surampalli R.Y., Zhang T.C., Lamsal B.P., Tyagi R.D., Kao C.M. 2010. Bioenergy and Biofuel from Biowaste and Biomass, Ch. 1/24: 80-81.

[9] Coats E.R., Gregg M., Crawford R.L., 2011. Effect Of Organic Loading And Retention Time On Dairy Manure Fermentation. Bioresource Technology, 102, 2572-2577.

[10] Li R., Chen S., Li X. 2010. Biogas Production from Anaerobic Co-digestion of Food Waste with Dairy Manure in a Two-Phase Digestion System, Applied Biochemistry and Biotechnology, 160, 643-654.

[11] Gerardi M.H. 2003. The Microbiology Of Anaerobic Digesters: John Wiley \& Sons Inc., 51-57. New Jersey.

[12] Hassan E. A. 2003. Biogas Production From Forage And Sugar Beets; Process Control and Optimization-Ecology and Economy, University of Kassel Faculty of Ecological Agricultural Sciences Department of Agricultural Engineering in the Tropics and Subtropics, Kassel/Almanya.

[13] Kaya D., Tırıs M., Yaldız O., Saraç H.I.., Ekinci K., Koçar G., Karaman N., Ayan E., Saraç M. 2009. Bitkisel ve Hayvansal Atıklardan Biyogaz Üretimi ve Entegre Enerji Üretim Sisteminde Kullanımı (Biyogaz) Projesi, Mühendis ve Makine Dergisi, Sayı: 593.

[14] Lague C., Landry H., Roberge M. 2005. Engineering Of Land Application Systems For Livestock Manure: A Review, Canadian Biosystems Engineering/ Le Génie Des Biosystèmes Au Canada, 47, 6.17- 6.28.

[15] Türkiye İstatistik Kurumu, https://biruni.tuik.gov.tr/ilgosterge/?locale=tr (Erişim Tarihi: 06.07.2018).

[16] T.C. Tarım ve Orman Bakanlı̆̆ı, www.tarim.gov.tr (Erişim Tarihi: 11.11.2018)

[17] Deublein D., Steinhauser A. 2008. Biogas from waste and renewable resources; an introduction, WILEY-VCH Verlag GmbH \&Co. KGaA, Almanya.

[18] Kılıç F. Ç., 2011. Biyogaz, Önemi, Genel Durumu ve Türkiye'deki Yeri. Mühendis ve Makine Dergisi, 52, 94-106.

[19] Gençoğlan S., Gençoğlan C., Başpnar A., 2015. Kahramanmaraş Ili'nin Hayvansal Kaynakli Biyogaz Potansiyelinin Belirlenmesi. 1. Ulusal Biyosistem Mühendisliği Kongresi, 1-7, Bursa. 
[20] Ardıç I., Taner F. 2005. Biyokütleden Biyogaz Üretimi: Anaerobik Arıtımın Temelleri. Yenilenebilir Enerji Kaynakları Sempozyumu ve Sergisi, Mersin, 242-245.

[21] Yıldız Ş., Saltabaş F., Balahorli V., Sezer K., Yağmur K. 2009. Organik Atıklardan Biyogaz Üretimi Projesi: Istanbul Örneği, Türkiye'de Katı Atık Yönetimi Sempozyumu, İstanbul, 1-8.

[22] Türker G., Aydın S., Akyol Ç., Yenigün O., İnce O., İnce B. 2016. Changes In Microbial Community Structures Due To Varying Operational Conditions In The Anaerobic Digestion Of Oxytetracycline-Medicated Cow Manure, Environmental Biotechnology.

[23] Şenol H., Elibol E.A., Açıkel Ü., Şenol M. 2017. Türkiye'de Biyogaz Üretimi İçin Başlıca Biyokütle Kaynakları, BEÜ Fen Bilimleri Dergisi, 6 (2): 15-28.

[24] Ziauddin Z., Rajesh R. 2015. Production and Analysis of Biogas from Kitchen Waste, International Research Journal of Engineering And Technology, 2 (4): 622-632.

[25] Öztürk M. 2017. Hayvan Gübresinden Biyogaz Üretimi, T.C. Çevre ve Orman Bakanlığı, Ankara.

[26] Ergürer H.S., Okumuş F. 2010. Cost And Potential Analysis Of Biogas İn Eskisehir, Uludağ Üniversitesi Mühendislik-Mimarlık Fakültesi Dergisi, 15 (2): 155.

[27] Nesteren B. 2003. Tarım ve Köy İşleri Bakanlığ1 Köy Hizmetleri Genel Müdürlüğü Ankara Enstitüsü, Ankara.

[28] T.C. Enerji ve Tabii Kaynaklar Bakanlığı, https://www.enerji.gov.tr/File/?path=ROOT\%2F1\%2FDocuments\%2FSayfalar\%2FBiyogaz+\% C3\%9Cretiminin+Mikrobiyolojisi.pdf (Erişim Tarihi: 01.10.2019).

[29] https://www.muhendisbeyinler.net/biyogaz-nedir-nasil-elde-edilir/ (Erişim Tarihi: 01.10.2019).

[30] Deviren H., İlkııı̧ C., Aydın S. 2017. Biyogaz Üretiminde Kullanılabilen Materyaller Ve Biyogazın Kullanım Alanları, Batman Üniversitesi Yaşam Bilimleri Dergisi, Cilt 7, Sayı 2/2, 82.

[31] Yetiş A.D., Gazigil L., Yetiş R., Çelikezen B. 2019. Hayvansal Atık Kaynaklı Biyogaz Potansiyeli: Bitlis Örneği, Academic Platform Journal of Engineering and Science 7-1: 74-78.

[32] Baran M.F., Lüle F., Gökdoğan O., 2017. Adıyaman İlinin Hayvansal Atıklardan Elde Edilebilecek Enerji Potansiyeli, Türk Tarım ve Doğa Bilimleri Dergisi, 4 (3): 245-249. 